\title{
Association/Dissociation of a Channel-Kinase Complex Underlies State-Dependent Modulation
}

\author{
Neil S. Magoski ${ }^{1}$ and Leonard K. Kaczmarek ${ }^{2}$ \\ ${ }^{1}$ Department of Physiology, Queen's University, Kingston, Ontario, Canada K7L 3N6, and 2Department of Pharmacology, Yale University, New Haven, \\ Connecticut 06520
}

\begin{abstract}
Although ion channels are regulated by protein kinases, it has yet to be established whether the behavioral state of an animal may dictate whether or not modulation by a kinase can occur. Here, we describe behaviorally relevant changes in the ability of a nonselective cation channel from Aplysia bag cell neurons to be regulated by protein kinase C (PKC). This channel drives a prolonged afterdischarge that triggers the release of egg-laying hormone and a series of reproductive behaviors. The afterdischarge is followed by a lengthy refractory period, during which additional bursting cannot be elicited. Previously, we reported that, in excised inside-out patches, the cation channel is closely associated with PKC, which increases channel activity. We now show that this channel-kinase association is plastic, because channels excised from certain neurons lack PKC-dependent modulation. Although direct application of PKC-activating phorbol ester to these patches had no effect, exposing the neurons themselves to phorbol ester reinstated modulation, suggesting that an absence of modulation was attributable to a lack of associated kinase. Furthermore, modulation was restored by pretreating neurons with either PP1 [4-amino-5-(4-methylphenyl)-7-( $t$-butyl)pyrazolo[3,4-d]pyrimidine] or SU6656, inhibitors of Src tyrosine kinase, an enzyme whose Src homology 3 domain is required for channel-PKC association. Neurons that were stimulated to afterdischarge and had entered the prolonged refractory period were found to have more phosphotyrosine staining and less channel-PKC association than unstimulated neurons. These findings suggest that Src-dependent regulation of the association between the cation channel and PKC controls both the long-term excitability of these neurons and their ability to induce reproduction.
\end{abstract}

Key words: Aplysia; bag cell neurons; nonselective cation channel; protein kinase C; metaregulation; excitability

\section{Introduction}

The control of neuronal excitability is often achieved through kinase-dependent regulation of ion channel activity (Hille, 2001; Levitan and Kaczmarek, 2001; Magoski and Kaczmarek, 2004). To orchestrate this regulation, kinases can be targeted directly to ion channels (Holmes et al., 1996; Tsunoda et al., 1997; Yu et al., 1997; Tibbs et al., 1998; Davare et al., 2001) in an association that amounts to a physical link, such that kinase-dependent regulation of the channel can be observed even in cell-free patches or bilayers (Rehm et al., 1989; Chung et al., 1991; Bielefeldt and Jackson, 1994; Wang and Kotlikoff, 1996; Wilson et al., 1998, Magoski et al., 2002). However, the extent to which these associations are regulated and the physiological consequence of any change in such arrangements remains poorly understood.

The bag cell neurons of the marine mollusc, Aplysia califor-

Received May 12, 2005; revised July 22, 2005; accepted July 26, 2005.

This work was supported by a Canadian Institutes of Health operating grant, a Canada Foundation for Innovation New Opportunities grant, an Ontario Innovation Trust New Opportunities grant, and a Queen's University Research Initiation grant (N.S.M.), as well as a National Institutes of Health operating grant (L.K.K.). We are very grateful to S. L. Smith for excellent technical assistance, J. Millete and A. Y. Hung for assistance with immunocytochemistry, Dr B. M. Olivera and J. S. Imperial for providing lyophilized Conus textile venom, Drs. D. J. Goldberg and B. H. White for advice on immunocytochemistry, and N. M. Magoski for both advice on immunocytochemistry and critical evaluation of previous drafts of this manuscript.

Correspondence should be addressed to Dr. N. S. Magoski, Department of Physiology, Queen's University, Fourth Floor, Botterell Hall, 18 Stuart Street, Kingston, Ontario, Canada K7L 3N6. E-mail: magoski@post.queensu.ca. DOI:10.1523/JNEUROSCI.1903-05.2005

Copyright $\odot 2005$ Society for Neuroscience $\quad$ 0270-6474/05/258037-11\$15.00/0 nica, control a series of behaviors culminating in egg laying. During synaptic stimulation, these peptidergic neurons undergo an $\sim 30$ min afterdischarge of action potential bursting that causes the release of egg-laying hormone (Kupfermann, 1967; Kupfermann and Kandel, 1970; Pinsker and Dudek, 1977; Rothman et al., 1983). The onset of the afterdischarge is associated with a number of well defined biochemical and biophysical changes (Conn and Kaczmarek, 1989), including activation of a nonselective cation channel that provides the depolarizing drive for bursting (Wilson and Kaczmarek, 1993, Wilson et al., 1996). Protein kinase $\mathrm{C}(\mathrm{PKC})$ is closely associated with the cation channel. This interaction persists in excised inside-out patches and serves to enhance activity through phosphorylation of the channel (Wilson et al., 1998; Magoski et al., 2002). Following the afterdischarge, the neurons enter an $\sim 18 \mathrm{~h}$ refractory period, during which a second afterdischarge and ensuing second bout of reproductive behaviors cannot be initiated. Although induction of the refractory period involves $\mathrm{Ca}^{2+}$ influx (Kaczmarek and Kauer, 1983; Magoski et al., 2000) and upregulation of $\mathrm{Ca}^{2+}$-activated $\mathrm{K}^{+}$current (Zhang et al., 2002), an understanding of how this dramatic drop in excitability is achieved remains incomplete.

We now show that PKC is not always linked to the cation channel in membrane patches. Our previous work indicated that the channel-PKC association required Src homology 3 (SH3) domain protein-protein interactions (Magoski et al., 2002). Consistent with this, we now find that the channel-PKC associ- 
ation can be regulated by Src tyrosine kinase itself. More significantly, the state of channel-PKC association depends on the state of neuronal excitability at the time of recording. In particular, the channel-PKC association is lost in the transition to the refractory period, suggesting that its absence represents a molecular homolog of refractoriness.

Abraham and Bear (1996) introduced the term "metaplasticity" to refer to a higher order of plasticity in which synaptic plasticity and/or the ability to induce plasticity was itself subject to change. Our findings support an analogous phenomenon regarding ion channel regulation, i.e., metaregulation, or the regulation of ion channel regulation. Metaregulation of channel-kinase interactions may result in cycles of association-dissociation, which can influence both the excitability of neurons and the behaviors they control for many hours.

\section{Materials and Methods}

Animals and cell culture. Adult Aplysia californica weighing 150-300 g were obtained from Marine Specimens Unlimited (San Francisco, CA) or Marinus (Long Beach, CA). Animals were housed in an $\sim 400 \mathrm{~L}$ aquarium containing continuously circulating, aerated sea water (Kent sea salt; Kent Marine, Acworth, GA) at $14-16^{\circ} \mathrm{C}$ on an $12 \mathrm{~h}$ light/dark cycle and fed Romaine lettuce three to five times per week.

For primary cultures of isolated bag cell neurons, animals were anesthetized by an injection of isotonic $\mathrm{MgCl}_{2}$ ( $\sim 50 \%$ of body weight), and the abdominal ganglion was removed and treated with neutral protease $\left(13.33 \mathrm{mg} / \mathrm{ml}\right.$; catalog \#165859; Roche, Indianapolis, IN) for $18 \mathrm{~h}$ at $22^{\circ} \mathrm{C}$ dissolved in normal artificial sea water (nASW) (composition: $460 \mathrm{~mm}$ $\mathrm{NaCl}, 10.4 \mathrm{~mm} \mathrm{KCl}, 11 \mathrm{~mm} \mathrm{CaCl}_{2}, 55 \mathrm{~mm} \mathrm{MgCl}_{2}, 15 \mathrm{~mm}$ HEPES, $1 \mathrm{mg} / \mathrm{ml}$ glucose, $100 \mathrm{U} / \mathrm{ml}$ penicillin, and $0.1 \mathrm{mg} / \mathrm{ml}$ streptomycin, $\mathrm{pH} 7.8$ with $\mathrm{NaOH}$ ). Salts were obtained from Fisher Scientific (Ottawa, Ontario, Canada), ICN (Aurora, OH), or Sigma (St. Louis, MO). The ganglion was then transferred to fresh nASW, and the bag cell neuron clusters were dissected from their surrounding connective tissue. Using a fire-polished Pasteur pipette and gentle titration, neurons were dispersed in nASW onto $35 \times 10 \mathrm{~mm}$ polystyrene tissue culture dishes (catalog \#430165; Corning, Corning, NY). Cultures were maintained in nASW for $1-3 \mathrm{~d}$ in a $14^{\circ} \mathrm{C}$ incubator, and, with certain exceptions, experiments were performed on neurons that were in vitro for at least $1 \mathrm{~d}$.

Excised inside-out patch-clamp recording. Single cation channel current was measured using an EPC-8 amplifier (HEKA Elektronik, Mahone Bay, Nova Scotia, Canada) and the excised inside-out patch-clamp method. Microelectrodes were pulled from 1.5-mm-internal-diameter borosilicate glass capillaries (catalog \#TW 150 F-4; World Precision Instruments, Sarasota, FL) and were fire polished to a resistance of 2-5 M $\Omega$ when filled with nASW (composition as above but lacking glucose, penicillin, and streptomycin). To lower the root mean squared noise of the current signal, microelectrode capacitance was reduced by coating the shank and half of the shoulder with dental wax (catalog \#92189; Heraeus Kulzer, South Bend, IN) under a dissecting microscope. After excision, the cytoplasmic face was bathed with artificial intracellular saline [composition in mM: $500 \mathrm{~K}$-aspartate, $70 \mathrm{KCl}, 0.77 \mathrm{CaCl}_{2}, 1.2 \mathrm{MgCl}_{2}, 10$ HEPES, 11 glucose, 5 EGTA, and 10 reduced glutathione, $\mathrm{pH} 7.3$ with $\mathrm{KOH}$; free $\left[\mathrm{Ca}^{2+}\right]$ of $1 \mu \mathrm{M}$, calculated using Ca buffer (courtesy of Dr. L. C. Schlichter, University of Toronto, Ontario, Canada)]. Salts were from Fisher Scientific, ICN, or Sigma. Current was low-pass filtered at 1 $\mathrm{kHz}$ using the EPC-8 Bessel filter and acquired at a sampling rate of 10 $\mathrm{kHz}$ using an IBM-compatible personal computer, a Digidata 1300 analog-to-digital converter (Axon Instruments, Union City, CA), and the Clampex acquisition program of pClamp (version 8; Axon Instruments). Data was gathered at $22^{\circ} \mathrm{C}$ in $1-3 \mathrm{~min}$ intervals while holding the patch at $-60 \mathrm{mV}$ or, to avoid occasional contamination by $\mathrm{Ca}^{2+}$. activated $\mathrm{K}^{+}$currents, $-80 \mathrm{mV}$. All experiments were performed on the more commonly encountered continuously active cation channels (defined as having relatively short closed times with uninterrupted openings and closings), as opposed to the rarely encountered bursting mode chan- nels [defined as having relatively long closed times and brief bursts of activity (Wilson and Kaczmarek, 1993)].

Extracellular recording. For extracellular recording, abdominal ganglia were set in a $14^{\circ} \mathrm{C}$ chamber, and a wide-bore, fire-polished glass suction electrode was placed at the rostral end of one of the pleuroabdominal connectives while a recording suction electrode was placed over the corresponding bag cell neuron cluster at the caudal end of the connective. Stimulating current pulses were delivered with a Grass S48 stimulator and isolation unit (Astro-Med, Longueuil, Quebec, Canada), while voltage was monitored using a Warner Instruments (Hamden, CT) DP-301 differential amplifier. The voltage was high-pass filtered at $0.1 \mathrm{~Hz}$ and low-pass filtered at $1 \mathrm{kHz}$ using the DP-301 filters and acquired at a sampling rate of $2 \mathrm{kHz}$ using an IBM-compatible personal computer, a Digidata 1300 analog-to-digital converter (Axon Instruments), and Axoscope software (version 8; Axon Instruments).

Immunocytochemistry. Bag cell neurons were stained for phosphotyrosine using an immunocytochemistry protocol adapted from $\mathrm{Wu}$ and Goldberg (1993) and White and Kaczmarek (1997). Neurons were plated in the center of small $(20-40 \mu \mathrm{l}$ ) wax rings (made from dental wax, as above) affixed to tissue culture dishes. For rapid solution changes, the dish was drained of all fluid except for the contents of the wax ring, and new solution was delivered by Pasteur pipette directly onto the neurons. Neurons were fixed for $25 \mathrm{~min}$ at room temperature with $4 \%$ (w/v) paraformaldehyde (catalog \#04042; Fisher Scientific) in $400 \mathrm{~mm}$ sucrose/ nASW (pH 7.5). They were then permeabilized for $5 \mathrm{~min}$ at room temperature with $0.3 \%(\mathrm{w} / \mathrm{v})$ Triton X-100 (catalog \#BP151; Fisher Scientific) in fix and washed two times with $\mathrm{PBS}$ [composition in mM: 137 $\mathrm{NaCl}, 2.7 \mathrm{KCl}, 4.3 \mathrm{Na}_{2} \mathrm{HPO}_{4}$, and $1.5 \mathrm{KH}_{2} \mathrm{PO}_{4}$, pH 7.0 with $\mathrm{NaOH}$ (salts from Fisher Scientific)]. Neurons were blocked for 30-60 min at room temperature in a blocking solution of $5 \%(\mathrm{v} / \mathrm{v})$ goat serum (catalog \#G9023; Sigma) in PBS. The primary antibody (monoclonal mouse antiphosphotyrosine IgG; clone 4G10; catalog \#05-321, lot 26349; Upstate Biotechnology; Lake Placid, NY) was applied at a 1:200 dilution in blocking solution, and the neurons were allowed to incubate for $1 \mathrm{~h}$ at room temperature. Neurons were then washed four times with PBS, and the secondary antibody (goat anti-mouse IgG FITC; catalog \#115-095-003, lot 61141; Jackson ImmunoResearch, West Grove, PA) was applied at a 1:200 dilution for $2 \mathrm{~h}$ in blocking solution at room temperature. Finally, neurons were washed four times with PBS, and the wax rings were filled with VectaShield (catalog \#H-1000; Vector Laboratories, Burlingame, CA) and covered with a glass coverslip (\#1; catalog \#48366045; VWR Scientific, West Chester, PA).

Stained neurons were imaged using a Nikon (Tokyo, Japan) TS100-F inverted microscope equipped with a Nikon Plan Fluor $20 \times$ objective (numerical aperture, 0.5 ). The light source was a $75 \mathrm{~W}$ xenon arc lamp and a multi-wavelength DeltaRAM V monochromatic illuminator (Photon Technology International, London, Ontario, Canada) coupled to the microscope with a UV-grade liquid-light guide. Between acquisition episodes, the excitation illumination was blocked by a shutter, which, along with the excitation wavelength, was controlled by a IBM-compatible personal computer, a Photon Technology International computer interface, and ImageMaster Pro software (version 1.49; Photon Technology International). Neurons were exposed to a excitation wavelength of 492 $\mathrm{nm}$, which was reflected off a $505 \mathrm{~nm}$ dichroic mirror, and the resulting emitted light then passed through a $520 \mathrm{~nm}$ barrier filter before being detected by a Photon Technology International IC200 intensified chargecoupled device camera. Single, full-frame $(520 \times 480$ pixels $)$ images were saved to disk for off-line analysis using NIH ImageJ (version 1.32) for quantitation and Corel Draw (version 7 or 10; Corel, Ottawa, Ontario, Canada) for presentation. Fluorescence intensities were quantitated using regions of interests defined over the entire neuronal somata and are reported as the mean gray value.

Reagents and drug application. Most drugs were introduced into the bath by pipetting a small volume $(<10 \mu \mathrm{l})$ of concentrated stock solution into the culture dish ( $2 \mathrm{ml}$ volume). Care was taken to pipette the stock near the side of the dish and as far away as possible from the microelectrode and patch. 4-Amino-5-(4-methylphenyl)-7-(t-butyl)pyrazolo [3,4-d]pyrimidine (PP1) (catalog \#EI-275) was obtained from Biomol (Plymouth Meeting, PA). Dimethylsulfoxide (DMSO) (catalog \#BP- 
231) was obtained from Fisher Scientific. Src tyrosine kinase (human, p60 ${ }^{\text {c-src }}$; catalog \#PK03) was from Oncogene Research Products (Cambridge, MA). GTP (sodium salt; catalog \#G8877), guanosine-5' - [ $\gamma$-thio] triphosphate (GTP $\gamma \mathrm{S})$ (tetralithium salt; catalog \#G8634), and phorbol 12-myristate 13-acetate (PMA) (catalog \#P8139) were obtained from Sigma. ATP was obtained from either Sigma (grade 2, disodium salt; catalog \#A3377) or from ICN (disodium salt; catalog \#194613).

Conus textile venom (CtVm) (Cruz et al., 1976) lyophilate was provided by Dr. B. M. Olivera of the University of Utah (Salt Lake City, UT). Crude $\mathrm{CtVm}$ was extracted using $0.5 \%$ (v/v) trifluoroacetic acid (catalog \#BP-618; Fisher Scientific) as described previously (Magoski et al., 2000, 2002). For experiments, aliquots of $\mathrm{CtVm}$ were diluted into $2 \mathrm{ml}$ of bath solution for a final protein concentration of $\sim 150 \mu \mathrm{g} / \mathrm{ml}$.

Single-channel and statistical analysis. To determine single-channel open probability $\left(P_{\mathrm{O}}\right)$ and make statistical descriptions of channel kinetics, events lists were made from single-channel data files using the halfamplitude threshold criterion (Colquhoun and Sigworth, 1995) of the Fetchan analysis program of pClamp. For analysis, most data did not require additional filtering below the $1 \mathrm{kHz}$ used during acquisition; however, to avoid inclusion of noise-related "events" as channel openings, some data were filtered a second time using the Fetchan digital Gaussian filter to a final cutoff frequency of $500 \mathrm{~Hz}$. For display in figures, some data were filtered to a final cutoff frequency of $500 \mathrm{~Hz}$. The Pstat analysis program of pClamp was used to read events lists and determine $P_{\mathrm{O}}$ for a given data file, either automatically or manually, but in both cases using the following formula: $P_{\mathrm{O}}=\left(t_{1}+t_{2}+\ldots t_{n}\right) / N \times t_{\text {tot }}$, where $t$ is the amount of time that $n$ channels are open, $N$ is the number of channels in the patch, and $t_{\text {tot }}$ is the time interval over which $P_{\mathrm{O}}$ is measured. The number of channels in the patch was determined by counting the number of unitary current levels, particularly at more positive voltages (typically $-20 \mathrm{mV}$ ). Pstat was also used to generate singlechannel open and closed dwell-time histograms and fit them with a sum of exponentials describing the kinetic behavior of the channel. The time interval ( $x$-axis) was binned logarithmically, and histograms were fit using the maximum likelihood estimator method and a simplex search (Colquhoun and Sigworth, 1995), which was given as the number of exponentials and estimated time constants ( $\tau$ values) at the start. Kinetic analysis was performed exclusively on patches that contained only one cation channel, as determined by a consistent display of a single open current level at more positive voltages (typically $-20 \mathrm{mV}$ ). These channels also had to have a high enough $P_{\mathrm{O}}$ such that there were sufficient events in the dwell-time histograms for reliable fitting. In practice, this translated into a minimum of 500 events for such histograms. Considering the recording periods used here (typically $3 \mathrm{~min}$ ), along with an average open time of $7.2 \pm 1.7 \mathrm{~ms}$, the $P_{\mathrm{O}}$ had to be at least 0.02 to generate 500 events (openings). Indeed, the $P_{\mathrm{O}}$ of the true single channels used for kinetic analysis was always above 0.02 and averaged $0.06 \pm 0.02$ before ATP and $0.38 \pm 0.12$ after ATP.

Data are presented as the mean and SEM. Statistical analysis was performed using Instat (version 3; GraphPad Software, San Diego, CA). Student's $t$ test was used to test whether the mean differed between two groups, and an ordinary one-way ANOVA followed by a Student-Newman-Keuls multiple comparisons test was used to test whether the means differed between three groups. The binomial probability and binomial test were used to test the likelihood that a dichotomous situation would occur a given number of times. Fisher's exact test, which examines the association between two variables, was used to test differences in frequency. Data were considered significantly different if the $p$ value was $<0.05$.

\section{Results}

\section{Effects of ATP on cation channel activity}

Cation channel activity was observed using excised inside-out patches from cultured bag cell neurons. It was possible to identify these channels based on their conductance $(25-30 \mathrm{pS} ; \sim 2 \mathrm{pA}$ at $-60 \mathrm{mV}$ ), voltage dependence of opening (an increase in $P_{\mathrm{O}}$ with depolarization), and absence of voltage-dependent inactivation. In previous work, we showed that application of ATP to the cy- toplasmic face of cation channel-containing patches produced an increase in channel $P_{\mathrm{O}}$ (Wilson et al., 1998; Magoski et al., 2002). We found that this increase in $P_{\mathrm{O}}$ was attributable to the activity of a closely associated PKC-like kinase phosphorylating the cation channel or some adjacent protein (Fig. 1A) (Wilson et al., 1998). Because modulation of the channel by PKC remains intact in excised patches, we assume that the channel and kinase are in some way closely associated, although it is not known whether the association is direct or mediated by a scaffolding protein.

In the present study, $42 \%$ of cation channel-containing patches show the increased $P_{\mathrm{O}}$ response (Fig. $1 \mathrm{~B}$ ); however, we also found that, for $27 \%$ of cation channels, application of ATP produces no change in $P_{\mathrm{O}}$ (Fig. $1 C$ ), whereas for the remaining $31 \%$ of channels, it elicits a decrease in $P_{\mathrm{O}}($ Fig. $1 D)$. The criteria for placing a cation channel in a given category are as follows: if the $P_{\mathrm{O}}$ showed an elevation of $25 \%$ or greater, it was considered an increased $P_{\mathrm{O}}$ response; if the $P_{\mathrm{O}}$ fell between -25 and $+25 \%$, it was considered a no-change $P_{\mathrm{O}}$ response; and if there was a $25 \%$ or greater drop in $P_{\mathrm{O}}$, then it was considered a decreased $P_{\mathrm{O}}$ response. An examination of the first versus second half of the control periods for all of the channels reported on in Figure 1, reveals a mean percentage change $P_{\mathrm{O}}$ over time of $0.3 \%$, with an $\mathrm{SD}$ of $\pm 10.9 \%$. Thus, the $\pm 25 \%$ change threshold reflects that, although small changes in $P_{\mathrm{O}}(5-10 \%)$ can be observed over several minutes under control conditions, it is truly extraordinary to see the $P_{\mathrm{O}}$ increase or decrease by $25 \%$ spontaneously. This threshold allows for an accurate classification of cation channel responses while avoiding inclusion of any contestable outcomes. A summary of the number of animals and cation channel-containing patches with increased $P_{\mathrm{O}}$ versus those that lack an increase in $P_{\mathrm{O}}$, i.e., no-change $P_{\mathrm{O}}$ or decreased $P_{\mathrm{O}}$, is given in Figure $1 E$. The average percentage change for increased $P_{\mathrm{O}}$, no-change $P_{\mathrm{O}}$, and decreased $P_{\mathrm{O}}$ ATP responses is in turn provided in Figure $1 F$. Although the no-change and decreased $P_{\mathrm{O}}$ ATP responses are certainly distinct, we will treat them as one group for the purposes of frequency analysis by the Fisher's test. These responses are also functionally opposite to the PKCdependent modulation (increased $P_{\mathrm{O}}$ ATP response) necessary for the cation channel to depolarize the bag cell neurons during the afterdischarge. Magoski (2004) reported that the decreased $P_{\mathrm{O}}$ ATP response is mediated by a closely associated protein kinase A (PKA) that presumably is targeted to the channel in a manner similar to PKC.

A surprising aspect of the nature of the cation channel response to ATP was that it depended on the specific animal from which the bag cell neurons were isolated. Almost all cation channels excised from neurons cultured from a single animal responded to ATP in the same way. As shown in Figure $1 E, 34$ animals yielded only increased $P_{\mathrm{O}}$ ATP response channels, whereas 49 animals yielded only no-change and decreased $P_{\mathrm{O}}$ ATP response channels. In addition to this, there were 15 animals that yielded a mix of channels that included all three types of responses. Based on the number of animals we used for recording, the binomial probability of encountering $83(34+49)$ of 98 $(34+49+15)$ animals that yielded exclusively increased $P_{\mathrm{O}}$ ATP response channels or no-change/decreased $P_{\mathrm{O}}$ ATP response channels is $5.77 \times 10^{-13}$, which corresponds to a two-tailed $p$ value of $<1.4 \times 10^{-12}$. Thus, the probability that random variation accounts for the finding that channels from an animal are exclusively increased $P_{\mathrm{O}}$ ATP response or no-change/decreased $P_{\mathrm{O}}$ ATP response rather than a mix of all three is small. Because of this, it was possible to assign a given animal to a category with a high degree of certainty. 
We have reported previously the kinetic profile of the increased $P_{\mathrm{O}}$ response to ATP (Wilson et al., 1998; Magoski et al., 2002). The channel shown in Figure $1 B$ is a true single channel, and the kinetic analysis of its behavior is given in Figure $1 G$. In control conditions (Fig. 1G, top graphs), the kinetic profile of the channel was best fit by a three-exponential component description for closed times $\left(\tau_{\mathrm{C} 1}, \tau_{\mathrm{C} 2}\right.$, and $\left.\tau_{\mathrm{C} 3}\right)$ and a two-exponential component description for open times $\left(\tau_{\mathrm{O} 1}\right.$ and $\left.\tau_{\mathrm{O} 2}\right)$. With ATP (Fig. $1 G$, bottom graphs), the number of exponentials for both the closed and open times remained the same, but some time constants describing the closed and open states were altered. Whereas $\tau_{\mathrm{C} 1}$ and $\tau_{\mathrm{C} 2}$ showed minor changes, $\tau_{\mathrm{C} 3}$ decreased quite conspicuously, and this is best seen by noting the leftward shift and overall reduction in the rightmost peak of the closed time histogram. In addition, whereas $\tau_{\mathrm{O} 1}$ showed little change, $\tau_{\mathrm{O} 2}$ was elevated somewhat. These changes are consistent with our previous published data showing that, after ATP, there is a large drop in $\tau_{\mathrm{C} 3}$ and a small increase in $\tau_{\mathrm{O} 2}$ (Wilson et al., 1998; Magoski et al., 2002). In the present study, we use the kinetic profile of the increased $P_{\mathrm{O}}$ ATP response as an indicator of restoration of PKC-dependent modulation of the cation channel. Nevertheless, the true single-channel conditions allowing for kinetic analysis were rare and usually limited to a single patch from a given data set (for criteria, see Materials and Methods).

\section{Modulation cannot be restored by G- protein activation, Conus venom, or direct application of phorbol ester}

An absence of PKC-dependent modulation could be attributable to some form of crosstalk between the kinase or channel and a second signaling molecule or pathway. One possibility is G-proteindependent regulation of the channel and/or kinase. For example, Zamponi et al. (1997) described crosstalk between G-proteins and PKC with respect to $\mathrm{Ca}^{2+}$ channel modulation. The intracellular saline bathing the cytoplasmic face of cation channels normally did not contain GTP, and any G-protein-dependent processes possibly required by $\mathrm{PKC}$ would not be supported. However, including $0.1 \mathrm{~mm}$ GTP or $1 \mathrm{~mm}$ GTP $\gamma \mathrm{S}$, to permit and/or enhance the functioning of any G-proteins present in the patch, did not restore the increased $P_{\mathrm{O}}$ ATP response $(n=7$ and 4$)$ (Fig. 2A,B,E).

Alternatively, PKC-dependent modulation may require that the neurons be ac-

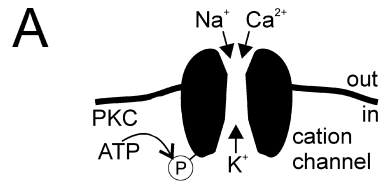

$B$ increased- $P_{\circ}$
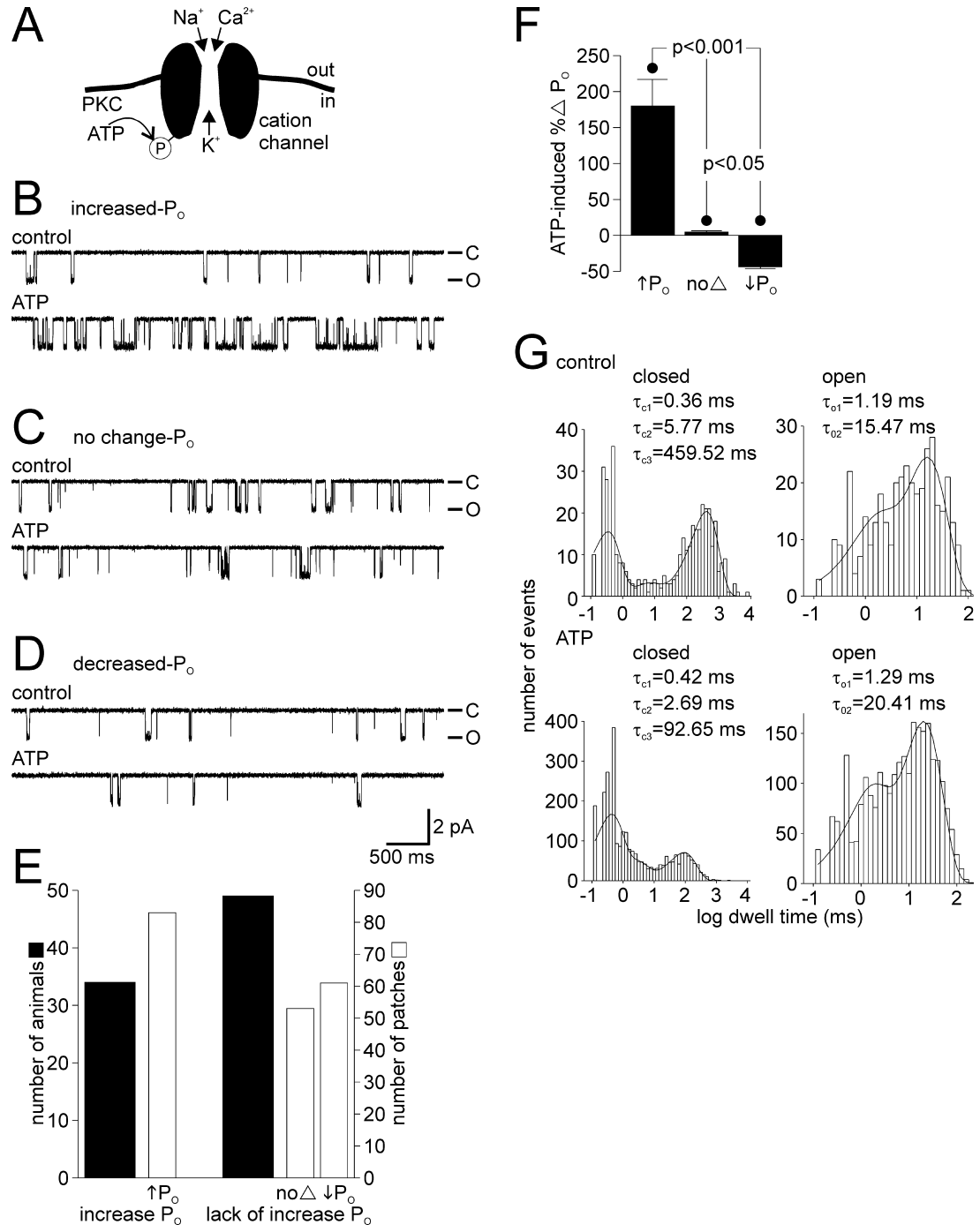

Figure 1. The cation channel can respond to ATP in three distinct ways. $\boldsymbol{A}$, Schematic diagram of the bag cell neuron cation channel showing its permeability and basis for regulation (based on Wilson et al., 1996, 1998; Magoski et al., 2002). With physiological solutions on both sides of a patch, $\mathrm{Na}^{+}, \mathrm{K}^{+}$, and $\mathrm{Ca}^{2+}$ pass through the channel. A closely associated PKC can use ATP as a phosphate source to phosphorylate either the channel or a nearby protein and increase activity. $\boldsymbol{B}$, Top trace, In an excised inside-out patch, at a holding potential of $-60 \mathrm{mV}$, the activity of the cation channel is seen as unitary inward current deflections of $\sim 2 \mathrm{pA}$. The closed state is at the top of the trace and designated by $-C$, whereas the open state is at the bottom and designated by -0 . Bottom trace, Bath application of $1 \mathrm{~mm}$ ATP to the cytoplasmic face of the patch produces a rapid and sustained increase in activity (in this particular example, the $P_{0}$ went from 0.039 to 0.337 ). The $P_{0}$ was calculated over the entire time of the control and ATP periods (usually $1-3$ min each). This increased $P_{0}$ ATP response was observed in $\sim 40 \%$ of the patches examined for the present study and is identical to what we have reported previously as a "typical" PKC-mediated ATP response (Wilson et al., 1998; Magoski et al., 2002). C, In 25\% of all patches, the response of the cation channel to ATP is absent altogether. The $P_{0}$ during the control period $(0.074$; top trace) shows no change when compared with the ATP period ( 0.073 ; bottom trace). The patch was held at $-60 \mathrm{mV}$. D, In the final $30 \%$ or 50 of patches, the addition of ATP results in a reduction of activity. There is a decrease in $P_{0}$ when comparing the control period $(0.019$; top trace) to the ATP period ( 0.013 ; bottom trace). The patch was held at $-60 \mathrm{mV}$. Amplitude and time base calibration bars also apply to $\boldsymbol{B}$ and $\boldsymbol{C}$. $\boldsymbol{E}$, A summary of animals (wide black bars) and patches (narrow gray bars) shows that animals either yield patches with cation channels that displayed an increase in $P_{0}$ to ATP or they yield patches with channels that lacked an increase in $P_{0}$, i.e., did not respond or had a decrease in $P_{0}$ with ATP. The classification criteria is that an increased response had to show a $>25 \%$ increase in $P_{0}$, a no-change response had to fall in between -25 and $+25 \%$ change in

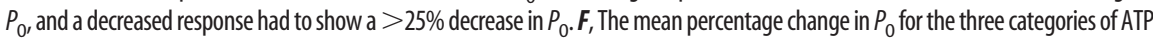
response compiled in $\boldsymbol{E}$. The increased $P_{0}$ ATP response averages an $\sim 180 \%$ elevation, the no-change $P_{0}$ ATP response averages an $\sim 4 \%$ rise, and the decreased $P_{0}$ ATP response averages an $\sim 40 \%$ drop in activity. All changes in $P_{0}$ are significantly different from one another ( $p<0.001$ or $p<0.05$, one-way ANOVA and Student-Newman-Keuls multiple comparisons test). $\mathbf{G}$, The channel shown in $\boldsymbol{B}$ is a true single channel, i.e., only one cation channel in the patch, which allows for kinetic analysis of its behavior. The single-channel closed and open dwell times are plotted as histograms along with the fit of a sum of exponentials, using the maximum likelihood estimator method and a simplex search. The time constants of the exponential fits are given in the inset of each graph. Under control conditions (top graphs), channel closed times are best fit by three exponentials $\left(\tau_{\mathrm{C} 1}, \tau_{\mathrm{C} 2}\right.$, and $\left.\tau_{\mathrm{C} 3}\right)$ and the open times by two exponentials $\left(\tau_{01}\right.$ and $\left.\tau_{02}\right)$. After the introduction of ATP (bottom graphs), the $\tau_{\mathrm{C}_{1}}$ or $\tau_{\mathrm{C}}$ change only to a small extent, whereas $\tau_{\mathrm{C} 3}$ is markedly reduced (a nearly 5 -fold decrease from $\sim 460$ to $\sim 90 \mathrm{~ms})$. Of the open times in the presence of ATP, $\tau_{02}$ displays a modest increase compared with $\tau_{01}$. This change in kinetic profile after ATP is qualitatively the same (a large change to $\tau_{\mathrm{C} 3}$ and a smaller change to $\tau_{02}$ ) as what we have reported previously (Wilson et al., 1998; Magoski et al., 2002). 


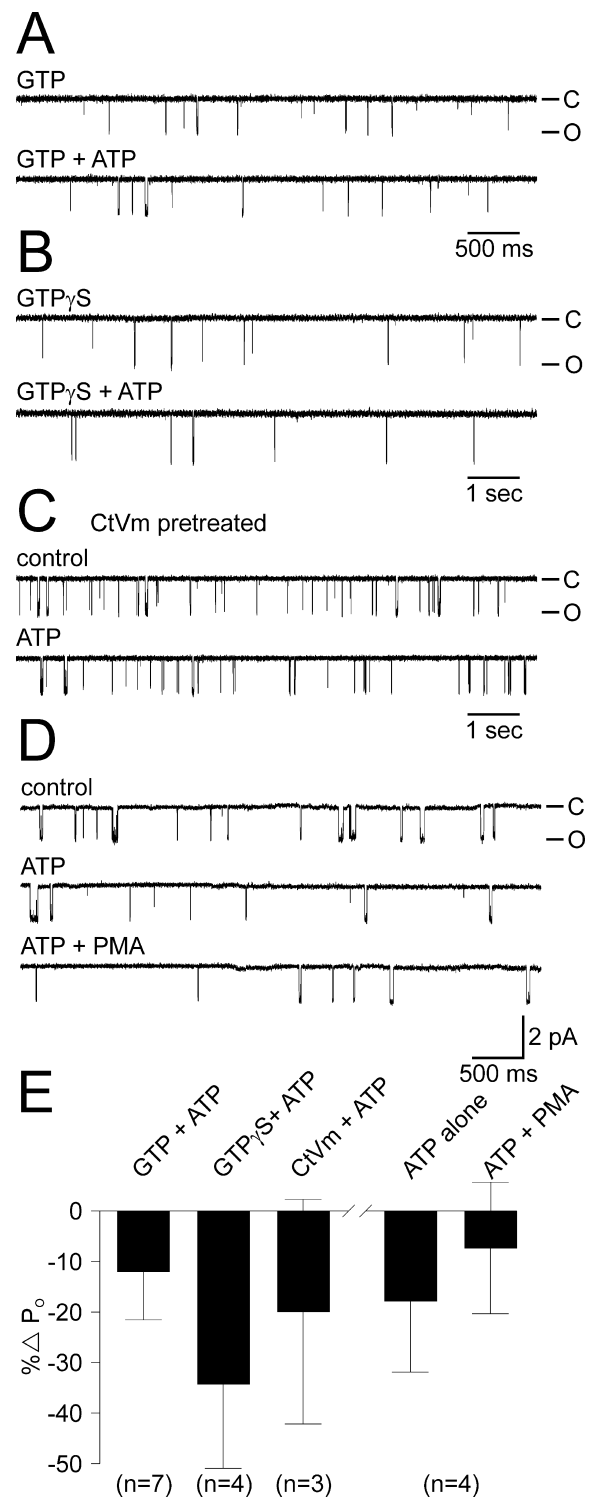

Figure 2. The ATP-induced $P_{0}$ increase could not be rescued by G-protein activation, Conus textile venom, or a subsequent attempt to activate PKC. $\boldsymbol{A}$, Top trace, A cation channelcontaining patch excised into $0.1 \mathrm{~mm} \mathrm{GTP}\left(P_{0}=0.006\right)$. Bottom trace, Channel activity does not increase with the addition of $1 \mathrm{~mm}$ ATP $\left(P_{0}=0.006\right)$. The patch was held at $-60 \mathrm{mV}$. For all of the experiments depicted in $\boldsymbol{A}-\boldsymbol{C}$, the patches were pulled from neurons that had been established previously as yielding no-change and decreased $P_{0}$ ATP response channels. $\boldsymbol{B}$, Top trace, A patch with a cation channel active at $-80 \mathrm{mV}$ (note larger current amplitude) excised into 1 mu GTP $\gamma S\left(P_{0}=0.004\right)$. Bottom trace, The activity of the channel does not increase with the addition of $1 \mathrm{~mm}$ ATP $\left(P_{0}=0.003\right)$. C, A neuron was pretreated with $150 \mu \mathrm{g} / \mathrm{ml}$ of a crude extract of $\mathrm{CtVm}$, a mixture known to depolarize cultured bag cell neurons and initiate afterdischarges in the intact cluster (Wilson et al., 1993, 1996; Magoski et al., 2000, 2002). However, after excision of a cation channel-containing patch, there is decrease in $P_{0}$ when the control period ( 0.045 ; top trace) is compared with the $1 \mathrm{~mm}$ ATP period $(0.035$; bottom trace). The patch was held at $-60 \mathrm{mV}$. D, For a channel displaying a decrease in $P_{0}$ to $1 \mathrm{~mm}$ ATP (top trace, control $P_{0}=0.0274$; middle trace, ATP $\left.P_{0}=0.0200\right)$, a subsequent attempt to activate any PKC potentially associated with the channel, by adding $100 \mathrm{~nm}$ of the phorbol ester PMA, does not produce a change in activity (bottom trace, ATP plus PMA $P_{0}=0.0195$ ). PMA was allowed access to the patch for a full $6 \mathrm{~min}$. The patch was held at $-60 \mathrm{mV}$. Amplitude calibration bar also applies to $\boldsymbol{A}-\boldsymbol{C}$. $\boldsymbol{E}$, Summary of initial attempts to rescue the ATP-induced increase in cation channel $P_{0}$. Neither exposure of the patch to GTP or GTP $\gamma S$, nor pretreating the neurons with CtVm results in increased $P_{0}$ ATP response channels. GTP $\gamma 5$ may have even enhanced the inhibitory response to ATP. The two rightmost bars summarize the experiments depicted in $\boldsymbol{D}$. The initial consequence of ATP on these cation channels is a slight inhibition, with the subsequent introduction of PMA being essentially without effect. The $n$ values refer to the number of patches. tively generating an afterdischarge. In an attempt to test this, we used extracellular application of a crude extract of venom from the molluscivorous marine snail, Conus textile (Olivera et al., 1990). CtVm reliably activates bag cell neurons both in culture and within their clusters in the nervous system. Evidence suggests that the $\mathrm{CtVm}$ response has many similarities to the afterdischarge itself and involves the binding of peptidergic component(s) to a membrane receptor with the subsequent production of second messengers (Wilson and Kaczmarek, 1993; Wilson et al., 1996; Magoski et al., 2000; Kachoei et al., 2004). Nevertheless, pretreatment of cultured bag cell neurons, previously found to yield no-change and decreased $P_{\mathrm{O}}$ ATP response cation channels, with $150 \mu \mathrm{g} / \mathrm{ml} \mathrm{CtVm}$ for 30-60 min, did not rescue the increased $P_{\mathrm{O}}$ ATP response in subsequent patches $(n=3)$ (Fig. 2C,E).

A lack of modulation could also be the result of the channelassociated PKC being inactive in the excised patch. Under these conditions, the addition of ATP would not result in phosphorylation or an increase in $P_{\mathrm{O}}$. To explore this possibility, cation channel-containing patches were excised and, if found to respond to ATP with no change or a decrease in $P_{\mathrm{O}}, 100-250 \mathrm{~nm}$ of the PKC-activating phorbol ester PMA was added to the cytoplasmic face of the patch $(n=4)$ (Fig. $2 D, E)$. In no case did the addition of PMA result in any significant change in $P_{\mathrm{O}}$. Although this does not rule out the possibility that an inactive PKC is in fact associated with the cation channel, the ineffectiveness of PMA, an agent that we have consistently found to be a very specific and potent activator of PKC in bag cell neurons (DeRiemer et al., 1985; Strong et al., 1987; Conn et al., 1989; Zhang et al., 2002), would suggest that either PKC is absent or in a configuration that renders it insensitive to PMA.

\section{Pretreatment with phorbol ester rescues modulation}

Direct application of PMA to the patch failed to bring about increased $P_{\mathrm{O}}$ ATP response cation channels from no-change or decreased $P_{\mathrm{O}}$ ATP response channels. If this were attributable to a lack of associated PKC in the first place, it should be possible to shift $\mathrm{PKC}$ to the membrane before patch excision by pretreating the neurons with PMA. Therefore, cultures were screened for ATP responsiveness, and, for those batches of neurons (from a single animal) found to consistently yield no-change $P_{\mathrm{O}}$ and decreased $P_{\mathrm{O}}$ ATP response channels, the remaining dishes were treated with either 100-250 nM PMA or the vehicle, DMSO. Exposing such neurons to PMA for 10-30 min rescued the increased $P_{\mathrm{O}}$ ATP response (Fig. $3 A$ ). The mean ATP-induced change in $P_{\mathrm{O}}$ for DMSO was $-14.5 \pm 10.8 \%(n=11)$, whereas with PMA, it was significantly different at $358.6 \pm 177.4 \%(n=$ $10 ; p<0.04$, Student's $t$ test) (Fig. $3 B$ ). Underlying this difference in the ATP-induced change in $P_{\mathrm{O}}$ was a significant shift in the frequency of specific responses to ATP with PMA pretreatment. In the DMSO group, there were five no-change $P_{\mathrm{O}}$ and five decreased $P_{\mathrm{O}}$ ATP response channels (10 in total) and only one increased $P_{\mathrm{O}}$ ATP response channel, whereas in the PMA group, there were two no-change $P_{\mathrm{O}}$ and two decreased $P_{\mathrm{O}}$ ATP response channels (four in total) and six increased $P_{\mathrm{O}}$ ATP response channels ( $p<0.03$, Fisher's exact test; no-change $P_{\mathrm{O}}$ and decreased $P_{\mathrm{O}}$ vs increased $\left.P_{\mathrm{O}}\right)$. The increased $P_{\mathrm{O}}$ ATP response cation channel from the PMA pretreated group (illustrated in Fig. $3 A$ ) is the one case for this dataset in which the patch contained a single ion channel, and its kinetic analysis is given in Figure $3 C$. The fitted closed state dwell times of the control versus ATP portion of the experiment revealed a clear drop in the duration of $\tau_{\mathrm{C} 3}$. Similarly, fitting the open state dwell times revealed a small 
elevation of the $\tau_{\mathrm{O} 2}$ duration. The changes to $\tau_{\mathrm{C} 3}$ and $\tau_{\mathrm{O} 2}$ were consistent with our previous findings describing the kinetics of the cation channel after a PKCdependent $P_{\mathrm{O}}$ increase (Wilson et al., 1998; Magoski et al., 2002). This supports the conclusion that the ATP-induced enhancement of $P_{\mathrm{O}}$ for cation channels excised from PMA-treated neurons is attributable to an associated PKC.

\section{Tyrosine phosphorylation influences} cation channel activity and modulation Magoski et al. (2002) examined the dependence of the channel-kinase complex on protein-protein interactions and found that the link between channel and kinase requires an $\mathrm{SH} 3$ domain. Specifically, only the $\mathrm{SH} 3$ domain and motif peptide from Src tyrosine kinase itself were capable of disrupting modulation. This made us consider the possibility that Src, either through tyrosine phosphorylation or as a scaffolding/marshalling protein, could influence the ability of PKC to modulate the cation channel.

We first investigated the effect of applying Src directly onto no-change and decreased $P_{\mathrm{O}}$ ATP response channels. Rather than rescuing $\mathrm{PKC}$-dependent modulation, when Src tyrosine kinase (human, p60 ${ }^{\mathrm{c}-\mathrm{src}}, 5-10 \mathrm{U} / \mathrm{ml}$ ) was delivered in the presence of ATP to the cytoplasmic face of cation channels, it reduced $P_{\mathrm{O}}$ by $-43.4 \pm 11.9 \%(n=11)$ (Fig. $\left.4 A\right)$. The Src-mediated inhibition could be prevented if the kinase was first mixed with the Src-family tyrosine kinase inhibitor PP1 (5 $\mu \mathrm{M}$ ) (Hanke et al., 1996) for $\sim 1$ min before addition (change in $P_{\mathrm{O}}$ of $0 \pm 10.9 \% ; n=7 ; p<0.03$, Student's $t$ test) (Fig. $4 B$ ). PP1 has been shown to be an effective Src inhibitor in Aplysia using a biochemical assay (Suter and Forscher, 2001).

Because Src itself had an inhibitory effect on cation channel activity, we then took the opposite approach and pretreated those neurons known to be yielding no-change and decreased $P_{\mathrm{O}}$ ATP response channels with the Src inhibitor PP1 ( $5 \mu \mathrm{M})$ and the sister cultures with the vehicle DMSO. Exposure to PP1 for 30-60 min resulted in restoration of the increased $P_{\mathrm{O}}$ ATP response (Fig. $5 A)$. For DMSO pretreatment, the mean ATP-induced change in $P_{\mathrm{O}}$ was $15.5 \pm 15.2 \%(n=11)$, but for PP1 pretreatment, it was significantly different at $244.8 \pm 112.8 \%(n=9 ; p<0.05$, Student's $t$ test) (Fig. $5 C$ ). A similar result was achieved by pretreating for 30-45 min with a structurally different Src-family tyrosine kinase inhibitor, SU6656 (5 $\mu \mathrm{M}$ ) (Blake et al., 2000) (Fig. $5 B)$. In this case, cation channels excised from the DMSO-treated cultures had a mean ATP-induced change in $P_{\mathrm{O}}$ of $-16.8 \pm$ $24.7 \%(n=8)$, whereas the SU6656 treatment resulted in a significantly different $P_{\mathrm{O}}$ change of $199.2 \pm 106.0 \%(n=7 ; p<$ 0.05 , Student's $t$ test) (Fig. $5 C$ ). There was also a significant shift in frequency of the specific response to ATP with both PP1 and SU6656 pretreatment. For PP1, there were one no-change $P_{\mathrm{O}}$ and two decreased $P_{\mathrm{O}}$ ATP response channels (three in total) and six increased $P_{\mathrm{O}}$ ATP response channels compared with six no change $P_{\mathrm{O}}$ and three decreased $P_{\mathrm{O}}$ ATP response channels (nine in total) and two increased $P_{\mathrm{O}}$ ATP response channels in the DMSO group $\left(p<0.04\right.$, Fisher's exact test; no-change $P_{\mathrm{O}}$ and

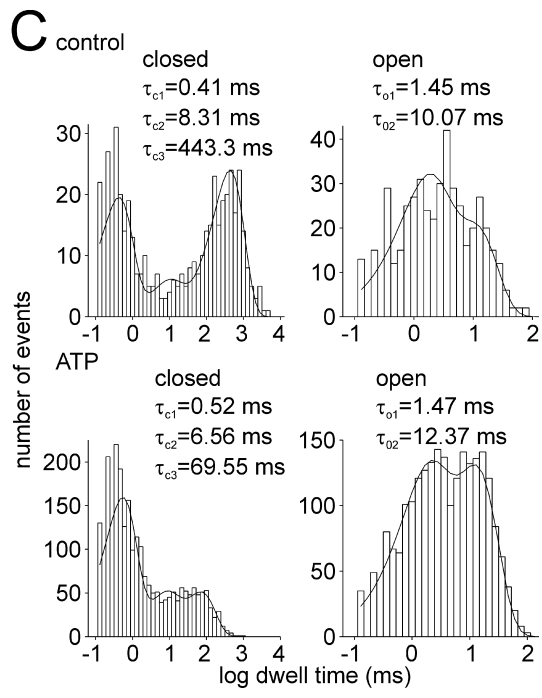

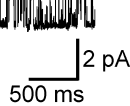

Figure 3. Previous activation of PKC in bag cell neurons rescues the ATP-induced increase in cation channel $P_{0}$. $A, A$ neuron from a culture that had been established previously as yielding no-change and decreased $P_{0}$ ATP response channels was preincrease in channel activity $\left(P_{0}=0.311\right)$. The patch was held at $-60 \mathrm{mV}, B$ Summary data of the ATP-induced change in $P$, cation channels excised from neurons pretreated with DMSO or PMA. Pretreating the neurons with PMA results in a signifi (the control period (top graphs) with the period (bottom graphs), the $\tau_{C_{3}}$ shows a large reduction (a nearly 6 -fold decrease from $\sim 440$ to $\sim 70 \mathrm{~ms}$ ) and the $\tau_{02}$ is seen to increase slightly. These changes are qualitatively the same as the example shown in Figure $1 G$, as well as what we have reported previously for the kinetic basis of a PKC-dependent increase in $P_{0}$ (Wilson et al., 1998; Magoski et al., 2002).

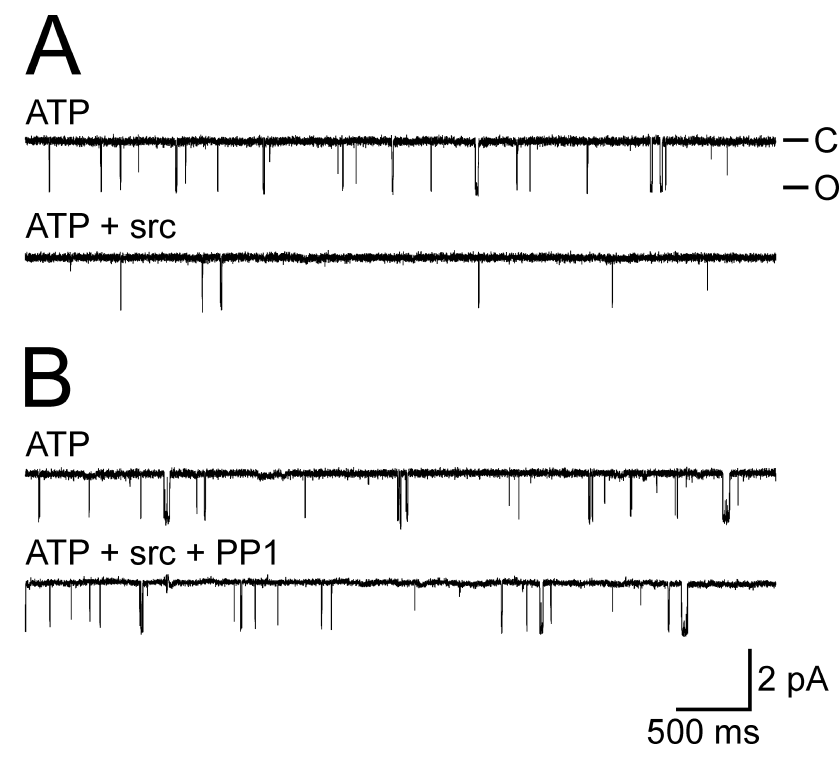

Figure 4. Src tyrosine kinase inhibits the cation channel. $\boldsymbol{A}$, Top trace, An excised control channel in the presence of $1 \mathrm{~mm}$ ATP $\left(P_{0}=0.020\right)$. Bottom trace, Application of $10 \mathrm{U} / \mathrm{ml}$ recombinant Srctyrosine kinase to the cytoplasmic face of the patch decreases the activity of the channel $\left(P_{0}=0.002\right)$. Representative of 11 experiments. The patch was held at $-60 \mathrm{mV}$. $\boldsymbol{B}$, Top trace, Another excised cation channel again in the presence of ATP $\left(P_{0}=0.0254\right)$. Bottom trace, Application of a mixture of $10 \mathrm{U} / \mathrm{ml}$ recombinant Src tyrosine kinase and $5 \mu \mathrm{m}$ of the Src-family inhibitor PP1 does not result in any significant change in activity $\left(P_{0}=0.0286\right)$. PP1 and Src were mixed for $\sim 1$ min before their addition. Representative of seven experiments. The patch was held at $-60 \mathrm{mV}$. Amplitude and time base calibration bars also apply to $\boldsymbol{A}$.

decreased $P_{\mathrm{O}}$ vs increased $\left.P_{\mathrm{O}}\right)$. Although for SU6656 there was one decreased $P_{\mathrm{O}}$ ATP response channel and six increased $P_{\mathrm{O}}$ ATP response channels compared with six decreased $P_{\mathrm{O}}$ ATP response channels and two increased $P_{\mathrm{O}}$ response channels in the 


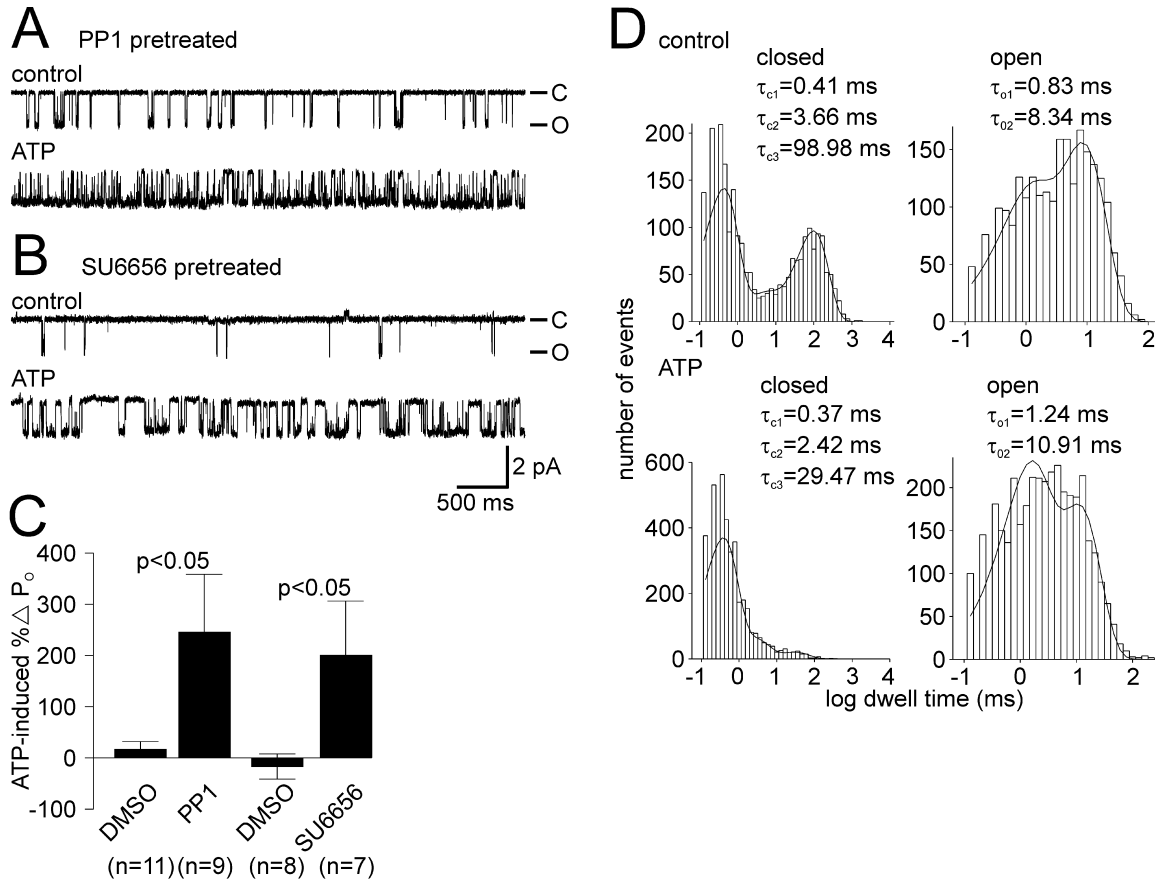

Figure 5. Previous inhibition of Src-family tyrosine kinases in bag cell neurons rescues the ATP-induced increase in cation channel $P_{0}$. A, A neuron from a culture that had been established previously as yielding no-change and decreased $P_{0}$ ATP response channels was pretreated with $5 \mu \mathrm{m}$ of the Src-family tyrosine kinase inhibitor PP1. Top trace, Control recording of single cation channel activity excised from the PP1 exposed neuron $\left(P_{0}=0.123\right)$. Bottom trace, Introduction of $1 \mathrm{~mm}$ ATP to the cytoplasmic face of the patch produces a robust increase in channel activity $\left(P_{0}=0.717\right)$. The patch was held at $-60 \mathrm{mV}$. $B, A$ neuron from a culture that again had been established as yielding no-change and decreased $P_{0}$ ATP response channels was pretreated with $5 \mu \mathrm{m}$ of the specific Src-family tyrosine kinase inhibitor SU6656. Top trace, Control recording of a cation channel excised from the SU6656-exposed neuron $\left(P_{0}=0.0072\right)$. Bottom trace, With the addition of $1 \mathrm{~mm}$ ATP to the cytoplasmic face of the patch, there is a marked elevation of channel activity $\left(P_{0}=0.0304\right)$. The patch was held at $-60 \mathrm{mV}$. Amplitude and time base calibration bars also apply to $A$. C, Summary data of the ATP-induced change in $P_{0}$ for cation channels excised from neurons pretreated with DMSO versus PP1 or SU6656. Pretreating the neurons with the Src inhibitors results in a significantly different change in $P_{0}$ after ATP when compared with DMSO-treated neurons from the same animals ( $p<0.05$, Student's $t$ test). $\boldsymbol{D}$, Kinetic analysis of the true single channel shown in $A$. A comparison of the control period (top graphs) and the ATP period (bottom graphs) shows that the $\tau_{C 3}$ is reduced ( $\mathrm{a}>3$-fold decrease from $\sim 99$ to $\sim 30 \mathrm{~ms}$ ) and the $\tau_{02}$ increases somewhat. Again, these changes are qualitatively the same as what we have reported previously as the kinetic basis of a PKC-dependent increase in $P_{0}$ (Wilson et al., 1998; Magoski et al., 2002).

DMSO group ( $p<0.04$, Fisher's exact test; no-change $P_{\mathrm{O}}$ and decreased $P_{\mathrm{O}}$ vs increased $\left.P_{\mathrm{O}}\right)$. Kinetic analysis of the channel shown in Figure $5 A$, an experiment in which only a single cation channel was present in the patch, revealed a pattern of changes similar to that seen after a standard PKC-dependent $P_{\mathrm{O}}$ increase (Fig. 5D, compare with Fig. 1G) (Wilson et al., 1998; Magoski et al., 2002). From the control period (Fig. 5D, top graphs) to the ATP period (Fig. $5 D$, bottom graphs), the $\tau_{\mathrm{C} 3}$ was reduced, whereas the $\tau_{\mathrm{O} 2}$ showed a small increase. Again this suggests that the ATP-induced enhancement of $P_{\mathrm{O}}$ for cation channels excised from PP1-treated neurons is attributable to an associated PKC.

Although inhibiting Src before patch excision rescued the modulation, it may be that Src inhibition in the patch itself permits PKC to function. To test this possibility, we determined whether modulation could be restored by inhibiting Src after a no-change or decreased $P_{\mathrm{O}}$ ATP response. When encountering such cation channels, $5 \mu \mathrm{M}$ PP1 was applied to the cytoplasmic face $(n=5)$ (Fig. $6 A$, traces $1-3, B)$. Delivering PP1 after the addition of ATP did not result in an increase in $P_{\mathrm{O}}$; furthermore, when PP1 was followed by $200 \mathrm{~nm}$ PMA (Fig. 6A, trace 4, B), to activate any PKC perhaps made available by Src inhibition, it still failed to bring about an elevation of $P_{\mathrm{O}}$. These data further sup- port the hypothesis that the no-change and decreased $P_{\mathrm{O}}$ ATP response cation channels lack an associated PKC.

\section{Immunocytochemically detected} phosphotyrosine is lower in resting as opposed to refractory bag cell neurons Because tyrosine phosphorylation appears to influence cation channel regulation both directly and indirectly, we examined phosphotyrosine levels in bag cell neurons to determine whether changes in tyrosine phosphorylation accompany the naturally occurring prolonged changes in their excitability. Phosphotyrosine was detected immunocytochemically using a monoclonal mouse IgG that has been widely used to stain for phosphotyrosine, including in Aplysia neurons (Wu and Goldberg, 1993). Staining of neurons cultured for $1 \mathrm{~d}$ showed both a uniform, diffuse signal over the entire soma, as well as a brighter, more intense signal near the membrane edge $(n=32)$ (Fig. 7A). This staining appeared to be specific, because omission of either the primary $(n=5)$ (Fig. $7 B)$ or secondary $(n=4)$ (Fig. 7C) antibody resulted in an absence of staining. Not surprisingly, pretreating the neurons for $30 \mathrm{~min}$ with either of the Src-family tyrosine kinase inhibitors PP1 $(n=7)$ (Fig. $7 D)$ or SU66565 $(n=9)$ (Fig. $7 E$ ) reduced the intensity of the staining. In this regard, PP1 appeared to be more effective than SU6656.

We next examined phosphotyrosine levels in bag cell neurons that were in one of their two different states of excitability, namely, resting and refractory. Only neurons that are in the resting phase can be stimulated to fire an afterdischarge, after which they enter the refractory period and additional afterdischarges cannot be stimulated (Conn and Kaczmarek, 1989). To investigate both resting and refractory neurons, abdominal ganglia were dissected from Aplysia and protease treated in preparation for cell isolation. The intact ganglia were then placed in the extracellular recording chamber and either left as control, unstimulated ganglia (resting) or, as shown in Figure $7 F$, the pleuroabdominal connective was stimulated to trigger an afterdischarge in the bag cell neurons (leading to the refractory state). Both unstimulated and stimulated ganglia were in the recording chamber for $\sim 60 \mathrm{~min}$, the only difference being that the stimulated ganglia were observed to fire an afterdischarge and found to be refractory when additional stimulation could no longer initiate bursting. Bag cell neurons were then isolated from the clusters within either of these ganglia and placed in the $14^{\circ} \mathrm{C}$ incubator for $3 \mathrm{~h}$, which provided sufficient time for the neurons to firmly adhere to the dish, before being fixed for immunocytochemistry.

Phosphotyrosine was detectable in resting bag cell neurons (Fig. 7G,I); however, the intensity of staining was muted compared with that of neurons in culture for $1 \mathrm{~d}$, i.e., such as those used in the single-channel studies (Fig. 7, compare $A, G$ ). This is in contrast to refractory neurons, which showed a greater overall 


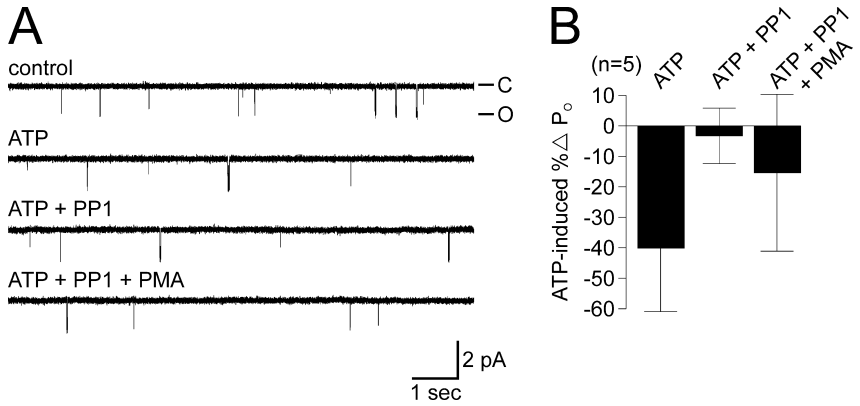

Figure 6. The ATP-induced $P_{0}$ increase could not be rescued by subsequent attempts to inhibit Src or activate PKC in the patch. $A$, A channel showing a modest decrease in $P_{0}$ to $1 \mathrm{~mm}$ ATP (first trace, control $P_{0}=0.0051$; second trace, ATP $P_{0}=0.0044$ ) does not display any recovery or increase in activity when either $5 \mu \mathrm{MPP} 1$ (third trace, $P_{0}=0.045$ ) or $200 \mathrm{~nm}$ PMA (fourth trace, $P_{0}=0.048$ ) are added in turn to the cytoplasmic face of the patch. The patch was held at $-60 \mathrm{mV}$. B. Summary of attempt to rescue the ATP-induced increase in cation channel $P_{0}$ in excised patches by Src inhibition and PKC activation. For these channels, ATP lowers the $P_{0}$ by an average of $\sim 40 \%$, and this is not reversed by the subsequent introduction of PP1 and PMA.

intensity of staining that included a frequent display of a prominent signal at the membrane edge (Fig. $7 H, I$ ). Although the phosphotyrosine staining was higher in refractory neurons versus resting neurons, the refractory neuron signal appeared only slightly greater than that of the neurons in culture for $1 \mathrm{~d}$ (Fig. 7, compare $A, H)$.

\section{PKC modulation is prevalent in resting, but not refractory,} bag cell neurons

The lower level of phosphotyrosine staining in resting neurons, combined with the restoration of modulation by Src inhibition, suggests a physiological role for the differences in the association between the channel and PKC in different animals. To address this compelling issue, we next examined the status of the channel-kinase complex in resting versus refractory neurons. The resting and refractory bag cell neurons were cultured as per the immunocytochemistry experiments. After a $3 \mathrm{~h}$ period in the $14^{\circ} \mathrm{C}$ incubator, the ATP response of the cation channel was examined using excised inside-out patch clamp. Patches were excised by $3.5-12 \mathrm{~h}$ after isolation, a timeframe that was still well within the $18 \mathrm{~h}$ refractory period.

Cation channels excised from resting bag cell neurons showed a mean ATP-induced change in $P_{\mathrm{O}}$ of $94.0 \pm 40.8 \%(n=7)$ (Fig. $8 A$ ), whereas patches excised from refractory neurons yielded cation channels with a mean ATP-induced change in $P_{\mathrm{O}}$ that was significantly different at $-2.2 \pm 19.9 \%(n=10 ; p<0.04$, Student's $t$ test) (Fig. $8 \mathrm{~B}$ ). As expected, the frequency of specific responses to ATP was significantly different in the resting neurons compared with those in the refractory state. For resting neurons, there was one no-change $P_{\mathrm{O}} \mathrm{ATP}$ response channel and six increased $P_{\mathrm{O}}$ ATP response channels, whereas the refractory neurons had four no-change $P_{\mathrm{O}}$ and three decreased $P_{\mathrm{O}}$ ATP response (seven in total) and three increased $P_{\mathrm{O}}$ ATP response channels $\left(p<0.04\right.$, Fisher's exact test; no-change $P_{\mathrm{O}}$ and decreased $P_{\mathrm{O}}$ vs increased $\left.P_{\mathrm{O}}\right)$. Figure $8 C$ shows the kinetic profile of the single cation channel patch from Figure $8 A$, and it is altered in a manner similar to that which occurs after a typical PKCdependent $P_{\mathrm{O}}$ increase (compare with Fig. $1 G$ ) (Wilson et al., 1998; Magoski et al., 2002). Specifically, there was a reduction in $\tau_{\mathrm{C} 3}$ from the control period (Fig. $8 \mathrm{C}$, top graphs) to the ATP period (Fig. $8 C$, bottom graphs), whereas a small increase was seen for $\tau_{\mathrm{O} 2}$. This supports the hypothesis that an associated PKC
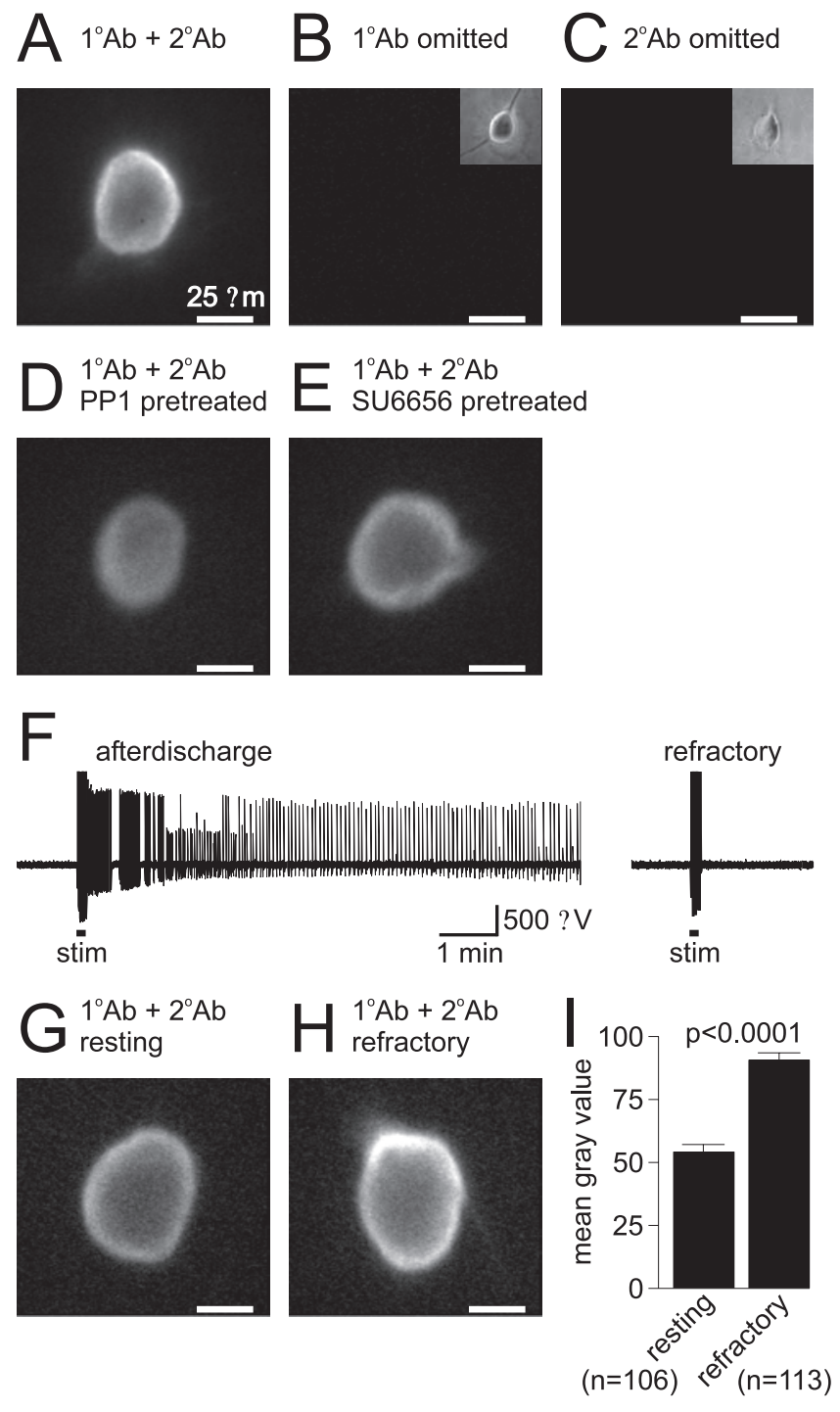

Figure 7. Resting bag cell neurons have less tyrosine phosphorylation than refractory bag cell neurons. A, Fluorescence staining of cultured bag cell neurons for phosphotyrosine. Staining of a 1-d-old bag cell neuron with both primary antibody $\left(1^{\circ} \mathrm{Ab}\right.$; monoclonal mouse antiphosphotyrosine lgG) and secondary antibody ( $\left(2^{\circ} \mathrm{Ab}\right.$; goat anti-mouse lgG FITC) shows a diffuse signal over the entire soma as well as a more prominent signal near the membrane edge. The scale bar applies to all pictures. $B$, If the $1^{\circ} \mathrm{Ab}$ is omitted and only the $2^{\circ} \mathrm{Ab}$ is used, the staining is absent. The inset in the top right corner shows the bright-field image of the neuron in the main picture. C, Similarly, if the $2^{\circ} \mathrm{Ab}$ is omitted and only the $1^{\circ} \mathrm{Ab}$ is used, there is no staining. The inset in the top right corner shows the bright-field image of the neuron in the main picture. D, Pretreatment of a 1-d-old bag cell neuron with $5 \mu \mathrm{M}$ PP1 reduces the intensity of staining, particularly near the membrane edge. $\boldsymbol{E}$, Although not quite as effective as PP1, pretreatment of a 1-d-old bag cell neuron with $5 \mu \mathrm{m}$ SU6656 also reduces the level of detected phosphotyrosine. $\boldsymbol{F}$, Extracellular recording from an intact bag cell neuron cluster in the abdominal ganglion. Left trace, Stimulation of the pleuroabdominal connective (stim; at bar, $2.5 \mathrm{~ms}$ pulses, $6 \mathrm{~Hz}, 10 \mathrm{~V}$ ) initiates an afterdischarge. Right trace, Approximately 40 min later, the cluster has ceased to fire and is refractory, as a subsequent stimulus does not induce a second afterdischarge. G, Staining of a neuron cultured from a resting bag cell neuron cluster, i.e., a cluster that had not undergone an afterdischarge. Although the diffuse staining is evident, the presence of signal at the membrane edge is not so prominent. $\boldsymbol{H}$, Staining of a neuron cultured using a refractory bag cell neuron cluster, i.e., a cluster that had been stimulated to fire an afterdischarge. Both the diffuse and membrane edge signals are conspicuous, and although these signals were certainly greater than those from the resting neurons, they were only slightly higher than what was observed in the 1-d-old cultured neurons. I, Summary data for the difference in fluorescence signal intensity, as measured using regions of interests over the entire neuronal somata and reported as the mean gray value. The signal from resting neurons is significantly different compared with refractory neurons ( $p<0.0001$, Student's $t$ test). 


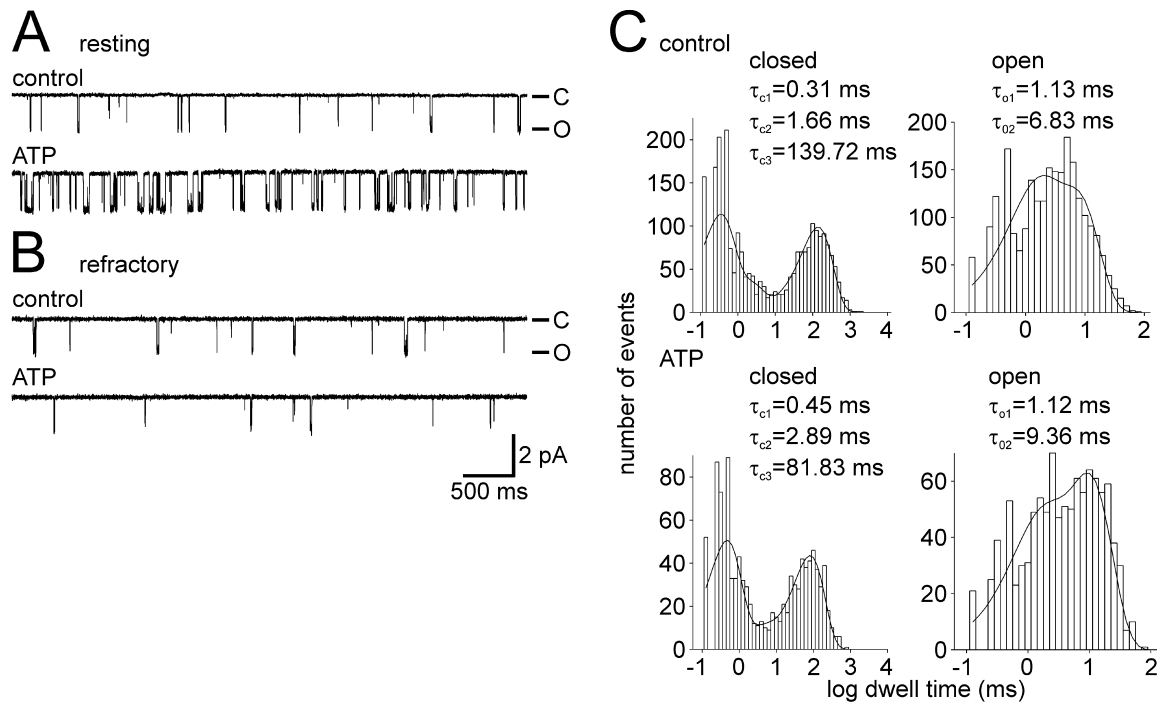

Figure 8. Resting and refractory bag cell neurons yield increased $P_{0}$ ATP response and no-change/decreased $P_{0}$ ATP response cation channels, respectively. $A$, Top trace, Control recording of single cation channel activity excised from a resting neuron $\left(P_{0}=\right.$ 0.0645). Bottom trace, Introduction of $1 \mathrm{~mm}$ ATP to the cytoplasmic face of the patch produces an increase in channel activity $\left(P_{0}\right.$ $=0.126)$. Representative of seven experiments. The patch was held at $-60 \mathrm{mV}$. $B$, Top trace, Control recording of single cation channel activity excised from a refractory neuron $\left(P_{0}=0.0043\right)$. Bottom trace, Introduction of $1 \mathrm{~mm}$ ATP to the cytoplasmic face of the patch results in decreased channel activity $\left(P_{0}=0.0012\right)$. Representative of 10 experiments. The patch was held at -60 $\mathrm{mV}$. Amplitude and time base calibration bars also apply to $\boldsymbol{A}$. $\boldsymbol{C}$, Kinetic analysis of the responsive channel shown in $\boldsymbol{A}$ (a true single channel). When the control period (top graphs) is compared with the ATP period (bottom graphs), $\tau_{C 3}$ is reduced (a near 2-fold decrease from $\sim 140$ to $\sim 82 \mathrm{~ms}$ ), and the $\tau_{02}$ increases somewhat. Again, these changes are qualitatively the same as what we have reported previously as the kinetic basis of a PKC-dependent increase in $P_{0}$ (Wilson et al., 1998; Magoski et al., 2002).

mediates the ATP-induced $P_{\mathrm{O}}$ increase for cation channels excised from neurons in the resting state.

\section{Discussion}

The bag cell neuron afterdischarge is characterized by a lengthy depolarization that is in part driven by a cation conductance (Kaczmarek and Strumwasser, 1984; Wilson and Kaczmarek, 1993; Wilson et al., 1996). At both the macroscopic and singlechannel level, this conductance is nonselective for cations, $\mathrm{Ca}^{2+}$ sensitive, voltage dependent, and non-inactivating (Wilson and Kaczmarek, 1993; Wilson et al., 1996; Magoski et al., 2002; Lupinsky and Magoski, 2004). Similar currents have been documented as underlying bursting in many, functionally diverse neurons from various species (Wilson and Wachtel, 1974; Partridge et al., 1979; Green and Gillette, 1983; Stafstrom et al., 1985; Swandulla and Lux, 1985; Alonso and Llinas, 1989; Rekling and Feldman, 1997; Beurrier et al., 1999; Morisset and Nagy, 1999; Egorov et al., 2002). In the bag cell neurons, PKC activity is elevated at the start of the afterdischarge (Wayne et al., 1999). Thus, the close association between the cation channel and PKC would expedite afterdischarge initiation by ensuring tight temporal coupling of enzyme activation to channel activation.

We now show that the PKC-dependent modulation is plastic. Forty-two percent of cation channels corresponding to $40 \%$ of animals/neurons showed an increased $P_{\mathrm{O}}$ ATP response, whereas 27 and $31 \%$ displayed a no-change and decreased $P_{\mathrm{O}}$ ATP response, respectively. We demonstrated previously that the ATPinduced $P_{\mathrm{O}}$ increase is attributable to a closely associated PKC (Wilson et al., 1998; Magoski et al., 2002). The no-change $P_{\mathrm{O}}$ ATP response seen in cation channels from some animals could have a number of explanations: one, PKC could be associated with the channel but is inactive; two, the channel could be in a state in which it cannot be phosphorylated or is in some way not respon- sive to phosphorylation; and three, the channel could lack an associated PKC. Because the application of PMA directly to the patch did not change the $P_{\mathrm{O}}$ of nochange and decreased $P_{\mathrm{O}}$ ATP response channels, it seems unlikely that the PKC is inactive but still associated. PMA is a potent and specific activator of PKC in bag cell neurons and, at the concentrations used, should have activated any associated PKC (DeRiemer et al., 1985; Manseau et al., 2001). This is corroborated by work on $\mathrm{Ca}^{2+}$-activated $\mathrm{K}^{+}$channels from rat brain extracts (Chung et al., 1991) and rat pituitary (Bielefeldt and Jackson, 1994), showing that associated $\mathrm{PKC}$ remains constitutively active after reconstitution into bilayers or excision. Although we cannot completely eliminate the second explanation (Catarsi and Drapeau, 1992), we feel the PMA pretreatment experiment argues against this conclusion. Rather, our finding that pretreating with PMA, which causes the bulk of the cytosolic PKC to translocate to the bag cell neuron plasma membrane (Sossin and Schwartz, 1994), restores modulation strongly supports the third explanation that no-change and decreased $P_{\mathrm{O}}$ ATP response channels lack an associated $\mathrm{PKC}$.

The finding that almost one-third of cation channels display a quantifiable decrease in $P_{\mathrm{O}}$ with ATP has been attributed recently to a PKA-like activity, closely associated with the channel (Magoski, 2004). That study also reported that, for channels displaying a decreased $P_{\mathrm{O}}$ ATP response, there was no enhancement of channel activity after pharmacological inhibition of PKA. Conversely, Wilson et al. (1998) reported that, for channels displaying an increased $P_{\mathrm{O}}$ ATP response, inhibition of PKC did not reveal an inhibitory component. This substantiates the concept that responsiveness is determined by the type of associated kinase (increased $P_{\mathrm{O}}$ ATP response is $\mathrm{PKC}$, decreased $P_{\mathrm{O}}$ ATP response is PKA, and no-change $P_{\mathrm{O}}$ ATP response is no kinase) and that PKC and PKA do not colocalize simultaneously with a given channel.

Our findings also indicate that the channel-PKC association itself can be regulated and that inhibition of Src tyrosine kinase promotes the association. Previous work has shown that tyrosine phosphorylation can modulate cation channel activity; for example, Wilson and Kaczmarek (1993) found that tyrosine phosphorylation regulated channel gating mode. In particular, application of a protein tyrosine phosphatase could shift the channel from a gating mode characterized by very long closed times and brief bursts of activity (burster mode) to a mode characterized by shorter closed times with uninterrupted openings and closings (continuously active mode). However, this gating mode shift is kinetically quite distinct from that produced by PKC. Our previous work also demonstrated that the channel-PKC association could be disrupted by the $\mathrm{SH} 3$ domain and motif peptide from Src itself but not by similar domains and motifs from other proteins, including the related tyrosine kinases yes and abl (Magoski et al., 2002). This high degree of protein-protein interaction specificity suggests that, in addition to its kinase function, Src 
operates in a scaffolding or marshalling capacity for the channelPKC complex.

Src has been shown to alter the function of a number of ion channels, including inhibition of delayed rectifier $\mathrm{K}^{+}$currents (Holmes et al., 1996; MacFarlane and Sontheimer, 2000; Nitabach et al., 2001, 2002), and enhancement of NMDA receptors (Wang and Salter, 1994; Yu et al., 1997), the cystic fibrosis $\mathrm{Cl}^{-}$ channel (Fischer and Machen, 1996), and voltage-gated $\mathrm{Ca}^{2+}$ currents (Wijetunge and Hughes, 1995). In the present study, we found that exogenously applied Src significantly reduced cation channel $P_{\mathrm{O}}$, and this could be prevented by the Src-family tyrosine kinase inhibitor PP1. The concentration of exogenous Src used here $(5-10 \mathrm{U} / \mathrm{ml})$ is similar to that used in other studies in which Src was introduced into a cell or applied to a patch (7.5-30 $\mathrm{U} / \mathrm{ml})$. Suter and Forscher (2001) showed that PP1 substantially reduced staining on a Western blot of Aplysia CNS protein with a probe for a highly conserved autophosphorylation site on Srcfamily tyrosine kinases. This, along with the fact that both PP1 and SU6656 reduced phosphotyrosine staining in bag cell neurons, makes it likely that, during the pretreatment experiments, these antagonists inhibited an endogenous, Src-like enzyme in bag cell neurons.

Although direct application of Src inhibited the cation channel, PKC-dependent modulation could be restored by pretreating bag cell neurons with PP1 or SU6656. This suggests that the channel-PKC association is normally regulated by endogenous Src activity. Src could prevent the association of the channel and PKC by phosphorylating the channel or an associated protein. However, because Src may be an integral component that links PKC to the channel, an attractive possibility is that phosphorylation by Src influences the ability of Src itself to act as a constituent of the scaffold. Inhibiting Src phosphorylation may reinstate the Src-dependent link between PKC and the cation channel. The latter is a potentially novel function for Src and could represent an interesting dual usage, in which a kinase (Src) that has a direct effect on the channel itself is also be capable of controlling the access of a second enzyme (PKC) that too is a modulator of the channel.

A significant finding from the present study is that increased $P_{\mathrm{O}}$ ATP response channels correlate with resting bag cell neurons and no-change/decreased $P_{\mathrm{O}}$ ATP response channels with refractory neurons. Following an afterdischarge, the bag cell neurons are refractory and fail to respond to subsequent synaptic stimulation with a prolonged burst. The lack of PKC-dependent modulation of the cation channel (no-change and decreased $P_{\mathrm{O}}$ ATP responses) may represent a molecular homolog of the refractory period. Both the absence of closely associated PKC as well as the inhibitory effects of closely associated PKA are likely to contribute to the inability of the bag cell neurons to respond to additional stimulation. The distribution of increased $P_{\mathrm{O}}$ ATP response versus no-change and decreased $P_{\mathrm{O}}$ ATP response cation channels was gathered from neurons that had spent at least $1 \mathrm{~d}$ in culture. Because more than half of these channels failed to show an increase in $P_{\mathrm{O}}$ to ATP, it would suggest that a significant proportion of the standard cultured bag cell neurons, i.e., from a single animal, had entered some form of in vitro refractoriness during the $\sim 24 \mathrm{~h}$ after plating. If Src contributes to setting bag cell neuron excitability, then Src activity in resting neurons may be low, so as to allow formation of the channel-PKC complex (increased $P_{\mathrm{O}}$ ATP response). In refractory neurons, Src activity would be high and provide a direct inhibition of the cation channel as well as prevent its association with PKC. This possibility is reinforced by the immunocytochemical data showing greater phosphotyrosine staining in refractory neurons. In addition to promoting PKC dissociation from the cation channel, Src appears to enhance, or at least permit, PKA to associate (decreased $P_{\mathrm{O}}$ ATP response). One possibility would be that an absence of PKC makes it sterically favorable for PKA to associate. Obviously, the PKA association would not be guaranteed, only favored, over the $\mathrm{PKC}$ association, making possible an absence of either kinase (no-change $P_{\mathrm{O}}$ ATP response).

By analogy to synaptic metaplasticity (Abraham and Bear, 1996), the changes in the association between the cation channel and PKC may represent a comparable phenomenon of metaregulation, i.e., regulation of the opportunity for a channel to undergo modulation. This metaregulation could occur through long-term changes in the nature of the protein-protein interactions required for the channel-PKC association. Metaregulation also appears to be associated with different states of bag cell neuron excitability, which may influence afterdischarge generation and egg laying, phenomena central to Aplysia's propagation.

\section{References}

Abraham WC, Bear MF (1996) Metaplasticity: the plasticity of synaptic plasticity. Trends Neurosci 19:126-130.

Alonso A, Llinas RR (1989) Subthreshold $\mathrm{Na}^{+}$-dependent theta-like rhythmicity in stellate cells of entorhinal cortex layer II. Nature 342:175-177.

Beurrier C, Congar P, Bioulac B, Hammond C (1999) Subthalamic nucleus neurons switch from single-spike activity to burst firing mode. J Neurosci 19:599-609.

Bielefeldt K, Jackson MB (1994) Phosphorylation and dephosphorylation modulate a $\mathrm{Ca}^{2+}$-activated $\mathrm{K}^{+}$channel in rat peptidergic nerve terminals. J Physiol (Lond) 475:241-254.

Blake RA, Broome MA, Liu X, Wu J, Gishizky M, Sun L, Courtneidge SA (2000) SU6656, a selective src family kinase inhibitor, used to probe growth factor signaling. Mol Cell Biol 20:9018-9027.

Catarsi S, Drapeau P (1992) Loss of extrasynaptic channel modulation by protein kinase $\mathrm{C}$ underlies the selection of serotonin responses in an identified leech neuron. Neuron 8:275-281.

Chung S, Reinhart PH, Martin BL, Brautigan D, Levitan IB (1991) Protein kinase activity closely associated with a reconstituted calcium-activated potassium channel. Science 253:560-562.

Colquhoun D, Sigworth FJ (1995) Fitting and statistical analysis of singlechannel records. In: Single channel recording, Ed 2 (Sakmann B, Neher E, eds), pp 483-587. New York: Plenum.

Conn PJ, Kaczmarek LK (1989) The bag cell neurons of Aplysia. Mol Neurobiol 3:237-273.

Conn PJ, Strong JA, Azhderian EM, Nairn AC, Greengard P, Kaczmarek LK (1989) Protein kinase inhibitors selectively block phorbol ester- or forskolin-induced changes in excitability of Aplysia neurons. J Neurosci 9:473-479.

Cruz LJ, Corpuz G, Olivera BM (1976) A preliminary study of Conus venom protein. Veliger 18:302-308.

Davare MA, Avdonin V, Hall DD, Peden EM, Burette A, Weinberg RJ, Horne MC, Hoshi T, Hell JW (2001) A fl 2 adrenergic receptor signalling complex assembled with the $\mathrm{Ca}^{2+}$ channel $\mathrm{Ca}_{\mathrm{V}}$ 1.2. Science 293:98-101.

DeRiemer SA, Greengard P, Kaczmarek LK (1985) Calcium/phosphatidylserine/diacylglycerol-dependent protein phosphorylation in the Aplysia nervous system. J Neurosci 5:2672-2676.

Egorov AV, Hamam BN, Fransen E, Hasselmo ME, Alonso AA (2002) Graded persistent activity in entorhinal cortex neurons. Nature 420:173-178.

Fischer H, Machen TE (1996) The tyrosine kinase p60 ${ }^{\mathrm{c}-\mathrm{src}}$ regulates the fast gate of the cystic fibrosis transmembrane conductance regulator chloride channel. Biophys J 71:3073-3082.

Green DJ, Gillette R (1983) Patch- and voltage-clamp analysis of cyclic AMP-stimulated inward current underlying neurone bursting. Nature 306:784-785.

Hanke JH, Gardner JP, Dow RL, Changelian PS, Brissette WH, Weringer EJ, Pollock BA, Connelly PA (1996) Discovery of a novel, potent, and src family-selective tyrosine kinase inhibitor. J Biol Chem 271:695-701.

Hille B (2001) Ionic channels of excitable membranes, Ed 3. Sunderland, MA: Sinauer. 
Holmes TC, Fadool DA, Ren R, Levitan IB (1996) Association of Src tyrosine kinase with a human potassium channel mediated by SH3 domain. Nature 274:2089-2091.

Kachoei B, Imperial JS, Olivera BM, Magoski NS (2004) Actions of Conus textile venom on Aplysia bag cell neurons. Soc Neurosci Abstr 30:86.2.

Kaczmarek LK, Kauer JA (1983) Calcium entry causes a prolonged refractory period in peptidergic neurons of Aplysia. J Neurosci 3:2230-2239.

Kaczmarek LK, Strumwasser F (1984) A voltage-clamp analysis of currents underlying cyclic AMP-induced membrane modulation in isolated peptidergic neurons of Aplysia. J Neurophysiol 52:340-349.

Kupfermann I (1967) Stimulation of egg laying: possible neuroendocrine function of bag cells of abdominal ganglion of Aplysia californica. Nature 216:814-815

Kupfermann I, Kandel ER (1970) Electrophysiological properties and functional interconnections of two symmetrical neurosecretory clusters (bag cells) in abdominal ganglion of Aplysia. J Neurophysiol 33:865-876.

Levitan IB, Kaczmarek LK (2001) The neuron: cell and molecular biology, Ed 3. New York: Oxford UP.

Lupinsky DA, Magoski NS (2004) $\mathrm{Ca}^{2+}$-regulation of a non-selective cation channel from Aplysia bag cell neurons. Soc Neurosci Abstr 30:86.3.

MacFarlane SN, Sontheimer H (2000) Modulation of Kv1.5 current by src tyrosine phosphorylation: potential role in differentiation of astrocytes. J Neurosci 20:5245-5253.

Magoski NS (2004) Regulation of an Aplysia bag cell neuron cation channel by closely associated protein kinase A and a protein phosphatase. J Neurosci 24:6833-6841.

Magoski NS, Kaczmarek LK (2004) Protein kinases and neuronal excitability. In: Encyclopedia of neuroscience, Ed 3 (Adelman G, Smith BH, eds), CD-ROM. New York: Elsevier.

Magoski NS, Knox RJ, Kaczmarek LK (2000) Activation of a $\mathrm{Ca}^{2+}$ permeable cation channel produces a prolonged attenuation of intracellular $\mathrm{Ca}^{2+}$ release in Aplysia bag cell neurones. J Physiol (Lond) 522 2:271-283.

Magoski NS, Wilson, Kaczmarek LK (2002) Protein kinase modulation of a neuronal cation channel requires protein-protein interactions mediated by an Src homology 3 domain. J Neurosci 22:1-9.

Manseau F, Fan X, Hueftlein T, Sossine WS, Castellucci VF (2001) $\mathrm{Ca}^{2+}$. independent protein kinase C AplII mediates the serotonin-induced faciliation at depressed Aplysia sensorimotor synapses. J Neurosci 21:1247-1256.

Morisset V, Nagy F (1999) Ionic basis for plateau potentials in deep dorsal horn neurons of the rat spinal cord. J Neurosci 19:7309-7316.

Nitabach MN, Llamas DA, Araneda RC, Intile J, Thompson IJ, Zhou YI, Holmes TC (2001) A mechanism for combinatorial regulation of electrical activity: potassium channel subunits capable of functioning as Src homology 3-dependent adaptors. Proc Natl Acad Sci USA 98:705-710.

Nitabach MN, Llamas DA, Thompson IJ, Collins KA, Holmes TC (2002) Phosphorylation-dependent and phosphorylation-independent modes of modulation of Shaker family voltage-gated potassium channels by Src family protein tyrosine kinases. J Neurosci 22:7913-7922.

Olivera BM, River J, Clark C, Ramilo CA, Corpuz GP, Abogadie FC, Mena EE, Woodward SR, Hillyard DR, Cruz LJ (1990) Diversity of Conus neuropeptides. Science 249:257-263.

Partridge LD, Thompson SH, Smith SJ, Connor JA (1979) Current-voltage relationships of repetitively firing neurons. Brain Res 164:69-79.

Pinsker HM, Dudek FE (1977) Bag cell control of egg laying in freely behaving Aplysia. Science 197:490-493.

Rehm H, Pelzer S, Cochet C, Chambaz E, Tempel BL, Trautwein W, Pelzer D, Lazdunski M (1989) Dendrotoxin-binding brain membrane protein displays $\mathrm{a} \mathrm{K}^{+}$channel activity that is stimulated by both cAMPdependent and endogenous phosphorylations. Biochemistry 28:6455-6460.
Rekling JC, Feldman JL (1997) Calcium-dependent plateau potentials in rostral ambiguus neurons in the newborn mouse brain stem in vitro. J Neurophysiol 78:2483-2492.

Rothman BS, Weir G, Dudek FE (1983) Egg-laying hormone: direct action on the ovotestis of Aplysia. Gen Comp Endocrinol 52:134-141.

Sossin WS, Schwartz JH (1994) Translocation of protein kinase C in Aplysia neurons: evidence for complex regulation. Mol Brain Res 24:210-218.

Stafstrom CE, Schwindt PC, Chubb MC, Crill WE (1985) Properties of persistent sodium conductance and calcium conductance of layer V neurons from cat sensorimotor cortex in vitro. J Neurophysiol 53:153-170.

Strong JA, Fox AP, Tsien RW, Kaczmarek LK (1987) Stimulation of protein kinase C recruits covert calcium channels in Aplysia bag cell neurons. Nature 325:714-717.

Suter DM, Forscher P (2001) Transmission of growth cone traction force through apCAM-cytoskeletal linkages is regulated by Src family tyrosine kinase activity. J Cell Biol 155:427-438.

Swandulla D, Lux HD (1985) Activation of a nonspecific cation conductance by intracellular $\mathrm{Ca}^{2+}$ elevation in bursting pacemaker neurons of Helix pomatia. J Neurophysiol 54:1430-1443.

Tibbs VC, Gray PC, Catterall WA, Murphy BJ (1998) AKAP15 anchors cAMP-dependent protein kinase to brain sodium channels. J Biol Chem 273:25783-25788.

Tsunoda S, Sierralta J, Sun Y, Bodner R, Suzuki E, Becker A, Socolich M, Zuker CS (1997) A multivalent PDZ-domain protein assembles signalling complexes in a G-protein-coupled cascade. Nature 388:243-249.

Wang Y-T, Salter MW (1994) Regulation of NMDA receptors by tyrosine kinases and phosphatases. Nature 369:233-235.

Wang Z-W, Kotlikoff MI (1996) Activation of KCa channels in airway smooth muscle cells by endogenous protein kinase A. Am J Physiol 271:L100-L105.

Wayne NL, Lee W, Kim YJ (1999) Persistent activation of calcium-activated and calcium-independent protein kinase $\mathrm{C}$ in response to electrical afterdischarge from peptidergic neurons of Aplysia. Brain Res 834:211-213.

White BH, Kaczmarek LK (1997) Identification of a vesicular pool of calcium channels in the bag cell neurons of Aplysia californica. J Neurosci 17:1582-1595.

Wijetunge S, Hughes AD (1995) pp60 ${ }^{\text {c-src }}$ increases voltage-operated calcium channel currents in vascular smooth muscle cells. Biochem Biophys Res Commun 217:1039-1044.

Wilson GF, Kaczmarek LK (1993) Mode-switching of a voltage-gated cation channel is mediated by a protein kinase A-regulated tyrosine phosphatase. Nature 366:433-438.

Wilson GF, Richardson FC, Fisher TE, Olivera BM, Kaczmarek LK (1996) Identification and characterization of $\mathrm{C} \mathrm{Ca}^{2+}$-sensitive nonspecific cation channel underlying prolonged repetitive firing in Aplysia neurons. J Neurosci 16:3661-3671.

Wilson GF, Magoski NS, Kaczmarek LK (1998) Modulation of a calciumsensitive nonspecific cation channel by ATP via a closely-associated protein kinase. Proc Natl Acad Sci USA 95:10938-10943.

Wilson WA, Wachtel H (1974) Negative resistance characteristic essential for the maintenance of slow oscillations in bursting neurons. Science 186:932-934.

Wu D-Y, Goldberg DJ (1993) Regulated tyrosine phosphorylation at the tips of growth cone filopodia. J Cell Biol 123:653-664.

Yu X-M, Askalan R, Keil GJ, Salter MW (1997) NMDA channel regulation by channel-associated protein tyrosine kinase src. Science 275:674-678.

Zamponi GW, Bourinet E, Nelson D, Nargeot J, Snutch TP (1997) Crosstalk between $G$ proteins and protein kinase $C$ mediated by the calcium channel $\alpha_{1}$ subunit. Nature 385:442-446.

Zhang Y, Magoski NS, Kaczmarek LK (2002) Prolonged activation of $\mathrm{Ca}^{2+}$ activated $\mathrm{K}^{+}$current contributes to the long-lasting refractory period of Aplysia bag cell neurons. J Neurosci 22:10134-10141. 